\title{
Analysis and Detection of Precursor Chemicals Used in Preparation of Narcotic Drugs and Psychotropic Substances - A Forensic Perspective
}

\author{
Kanak Lata Verma ${ }^{1^{*}}$, Madhulika $\mathbf{S}^{2}$ and Sarin $\mathbf{R K}^{3}$ \\ Department of Chemistry, Forensic Science Laboratory, Government of National Capital Territory of Delhi, Rohini, Delhi-110085, India
}

*Corresponding author: Kanak Lata Verma, Forensic Science Laboratory, Government of National Capital Territory of Delhi, Rohini, Delhi-110085, India, Tel: 9999143034; E-mail: kanak.dfsl@gmail.com

Rec date: Jan 04, 2015 Acc date: Feb 23, 2015 Pub date: Feb 28, 2015

Copyright: ( 2015 Verma KL, et al. This is an open-access article distributed under the terms of the Creative Commons Attribution License, which permits unrestricted use, distribution, and reproduction in any medium, provided the original author and source are credited.

\section{Short Communication}

The harmless desire of man which commenced as a curious pursuit to explore and then synthesize certain hidden treasures of Mother Nature consisting of strange chemical compositions, which she herself produces niggardly has today gained monstrous propositions. It has become a curse spoiling generations and crippling nations. The illicit production, trafficking, consumption and abuse of drugs is a major global challenge eating into the fabrics of society, fuelling divisions along ethnic and religious lines, violating values of human dignity, harbouring crime and creating psychological wrecks. It spreads senseless violence, damaging fragile economy of developing nations, creating a climate of hate, fear and mistrust between neighbouring countries and last but not the least providing skeletal financial seamless support to transcontinental terrorism termed aptly as "Narcoterrorism" [1].

With the exception of cannabis, every illicit drug requires chemicals to be refined to its final, consumable form. Chemicals play two critical roles in the production of illegal drugs: as chemical inputs for the production of synthetic drugs such as methamphetamine, MDMA (3,4-methylenedioxymethamphetamine, commonly known as ecstasy), mecloqualone, methaqualone, mephedrone, and as refining agents and solvents for processing plant-based materials such as coca and opium poppy into drugs such as cocaine and heroin. Chemicals used in synthetic drug production are known as "PRECURSOR CHEMICALS" because they are incorporated into the drug product and are less likely to be substituted by other chemicals. The ones used to refine and process plant-based drugs are referred to as "Essential Chemicals" and can be readily replaced by other chemicals with similar properties.

The United Nations Convention against Illicit Traffic in Narcotic Drugs and Psychotropic Substances, 1988 identifies those precursors which are most crucial to the illicit manufacture of drugs. These are listed in Table-I and Table-II in Ref. [2,3] (Substances inscrites aux Tableaux I et II de la Convention de 1988) of the convention and are universally accepted as PRECURSORS. Currently, there are 23 substances listed in the Tables of the 1988 Convention [2,3]. These Precursor chemicals which are otherwise essential for the production of Narcotic Drugs and Psychotropic Substances(NDPS) have a wide legitimate use in the production of consumer goods like pharmaceuticals, fragrances, flavouring agents, petroleum products, fertilizers and paints also. The chemicals used in methamphetamine production are pseudoephedrine, ephedrine, and pharmaceutical preparations containing these substances (commonly known as "combination products"). Additionally, producers have developed chemicals similar to these products which have been very safely christened as analogues - in an effort to evade chemical control laws and with greater technical know-how about the precursors, criminal organizations have become increasingly innovative in circumventing controls [4]. Cooperation at the international level among countries, organizations and international bodies, or among the concerned entities and bodies inside one country, has become necessary to combat illicit trafficking in drugs and psychotropic substances and other offences linked thereto such as terrorism, violence, corruption and laundering proceeds of such crimes [5].

Prevention is an indispensable part of fighting terrorism. The scope of prevention, however, is very wide, and responsibilities are to be shared by all of us. It is here that the intelligence of scientific soldiers comes in to picture. The seizure, analysis and examination of 'Precursor Chemicals' in order to stop clandestine preparation of narcotic drugs and psychotropic substances is no doubt an integral part of the preparedness to support the controlling and regulating mechanism fighting the war against drugs and substance abuse globally. The chemical examination of various unknown seized exhibits which include rigorous classical analysis and precise instrumental detection is a very challenging task in itself and it becomes more onerous from the forensic perspective as the forensic scientists end up with exhibits in traces, sometimes miniscule amount sticking to the glassware's used in the clandestine synthesis is sent to the Forensic laboratory for identification. The application of relevant and apt complimentary scientific technique is the key to overcome the challenge of detecting the unknown chemical entities. With the passing of time, the courts have imposed increasingly stringent standards for forensic Scientists testifying as expert witnesses in trials involving illegal manufacture and use of drugs [6]. Rigorous methods are required to provide unequivocal evidence in criminal proceedings.

We at the Forensic Science Laboratory (FSL), Government of National Capital Territory of Delhi receive voluminous cases for forensic chemical examination of exhibits pertaining to NDPS and precursor chemicals in the chemistry division. We are sharing here in brief two of the very challenging cases recently undertaken by us .In case no I there was a seizure of thirty exhibits by the Directorate of Revenue Intelligence, Government of India. The exhibits were described as unknown powdery material presumed to be used in clandestine preparation of some illicit drug or an illicit preparation itself covered under NDPS Act, 1985, Republic of India. In case no II a seizure was done by the special cell of the Crime branch and a total of one hundred and fifty-two exhibits were sent for forensic chemical examination to us at FSL.

To detect the clandestine preparations/Exhibits we adopted a strategy based on two analytical steps: a preliminary general screening step for identifying all the "presumptive positives" even at the cost of including some "false positives", followed by a confirmation step aimed at maximizing the competency to identify, among the presumptive 
positives, the "true positives." After number of extractions, chromatographic separations the extracted samples were subjected to examination using classical methods and advanced techniques like Gas Chromatography (GC) coupled with Mass Spectroscopy (MS). FTIR (Fourier Transform Infrared Spectroscopy) was also used as a complimentary technique. For final screening we relied on standardized conditions of chromatographic separation and MS/MS detection. Recognition requires the match of the retention time and the product ion spectrum (acquired in selected reaction monitoring or full scan mode) of the unknown analyte with that of reference substances present in databases or libraries. We were successful in identifying in case no I that 4-Methylmethcathinone (4-MMC) was the common component in all the thirty exhibits. 4-Methylmethcathinone (Mephedrone or 4-MMC) is known by common street name: Meow Meow, meph ,drone, MCAT and is a synthetic stimulant (belonging to amphetamine/ cathinone family of drugs) having similar effects to MDMA, amphetamine, cocaine [7] and our findings corroborated with the previous studies done by Eman-Y-santali et.al. [8] who have characterised 4-MMC by the same techniques. In case no II a thorough scientific investigation was carried out for all the exhibits, most of which contained various combination of drugs including pseudoephedrine, tripolidine, cetirizine, acetaminophen and phenylpropanolamine. Two of the exhibits in this seizure were found to contain acetic acid (the most commonly used chemical agent in various steps in synthesis of amphetamine/methamphetamines) and potassium permanganate (common oxidizing agent) which are also scheduled in the list of the precursor chemicals as they are required at various stages of nearly all illicit drug manufacture. Clandestine chemists have alternative methods for producing methamphetamine. The two predominant methods both involve the reduction of ephedrine or pseudoephedrine to methamphetamine. Pseudoephedrine is the primary precursor chemical used in the production of methamphetamine. Many countries have enacted precursor control laws which limit the sale of over-the-counter cold medications which contain ephedrine or pseudoephedrine. Phenylpropanolamine is not a methamphetamine precursor, although it can be used as an amphetamine precursor [9]. The detection of all the compounds corroborated the fact that the seized exhibits were indeed a part of some clandestine illicit manufacture of controlled drugs.

It takes a little sporting spirit to acknowledge the fact that forensic science laboratories do play a central role in drug control because traditionally our laboratories have been branded as mere tools and rarely as resources or dignified partners. The fact is that the laboratory results/reports are a powerhouse of information both technical as well as statistical and can be of immense help to identify new potential threats, health hazards, social and economic ramifications of those related to new drugs, their manufacturing methods, new sources of drugs, their availability, new purities, cutting agents, new products and drug combinations. Forensic drug examination is considered to be very monotonous and has never been visualised as revolutionary because at the end of the day the credit goes either to the enforcement officers who were instrumental in the huge seizures or to the policymakers who walk away with all the accolades for placing a drug or precursor under regulatory control or introducing restrictions on the availability of a dependence-producing medicine only after the prevalence of the substance has been identified with the help of a laboratory.

For a forensic scientist the detection of the compound is no doubt incredibly exciting but the journey undertaken to arrive at the final conclusion and the profound learning experience associated therein is what the scientist cherishes as the sweetest memories of his endeavour in pursuit of truth and excellence in forensic examination of the exhibits.

\section{References}

1. Rohan G (2001) "The Lifeblood of Terrorist Organizations: Evolving Terrorist Financing Strategies". In: Alex P Schmid (ed.) Countering Terrorism through International Cooperation 182-185.

2. www.incb.org.

3. www.unodc.org.

4. King LA (2003) The Misuse of Drugs Act, RSC Publications.

5. Ghani SA (2011) International Cooperation Against Narcotic Drugs, Psychotropic Substances and Precursors, Legal Books House, Egypt, El Mahala El Kobra 241.

6. Narayan LJ (2010) Course Material provided at - Workshop on Forensic Reporting Procedure in NDPS Cases, National Institute of Forensic Science and Criminology, Ministry of Home Affairs, Government of India, Delhi.

7. Meyer MR (2010) Anal Bioanal Chem 397: 1225-1233.

8. Eman YS (2011) Synthesis, full chemical characterisation and development of validated methods for quantification of (+)-4-methylmethcathinone (mephedrone):a new "legal high", Journal of Pharmaceutical and Biomedical Analysis 56: 246-255.

9. Precursors and Chemicals frequently used in the Illicit manufacture of Narcotic Drugs and Psychotropic Substances, E/INCB/2012/4 United Nations Publication. 